\title{
ANÁLISE DO PROGRAMA DE GERENCIAMENTO DE RESÍDUOS SÓLIDOS DA ITAIPU BINACIONAL
}

\author{
An analysis of the Solid Wastes Management Program \\ of Itaipu Binacional
}

\author{
Cheila Fernanda Noé \\ Marcelo Antunes Nolasco ${ }^{2}$
}

\section{Resumo}

Ao longo das últimas décadas, o mundo vem passando por um importante processo de reestruturação, no qual a questão ambiental vem influenciando planejamentos e decisões nos diversos setores da sociedade, inclusive no ambiente dos negócios. A sociedade, o governo e as próprias empresas passaram a visualizar a necessidade de adoção de posturas proativas com relação às questões ambientais, o que desencadeou o surgimento de novas e mais complexas responsabilidades, principalmente para as empresas, como resultado das alterações sociais e ambientais que causam. Nesse sentido, a Itaipu Binacional vem incorporando a variável ecológica em seu planejamento estratégico e em sua estrutura organizacional e, dentre suas ações, instituiu o Programa de Gerenciamento de Resíduos Sólidos da Itaipu Binacional, com o objetivo de dispor adequadamente os resíduos gerados em suas atividades cotidianas. Nesse trabalho são analisados os aspectos ambientais, sociais, econômicos e institucionais envolvidos nesse programa, bem como as principais alterações para um melhor funcionamento, segundo informações obtidas por um questionário aplicado ao público interno da Usina Hidrelétrica Itaipu Binacional.

Palavras-chave: Usina hidrelétrica; Resíduos; Educação ambiental.

\section{Abstract}

In the last decades the world has been experimenting an important reorganization process, where the environmental issues has influenced plans and decisions in almost all sectors of society, as well as in business. Society, the government and the companies themselves have come to visualize the need of adopting active attitudes in relation to environmental issues, what caused the appearance of newer and more complex responsibilities, especially for the companies, as a result of the social and environmental changes they cause. Based on this, Itaipu Binacional has been incorporating the ecological variable in its strategical planning and in its organizational structure and, among its actions, it has created the Solid Wastes Management Program of Itaipu Binacional, with the goal of correctly arranging the wastes generated by its everyday activities. In this paper the environmental, social, economical and institutional aspects of this program are analyzed, as well as the main changes for a better functioning, according to information obtained through a survey applied to the internal public at the hydroelectric power plant.

Keywords: Hydroelectric plant; Solid wastes; Environmental education.

1 Bacharel em Turismo pela UNIOESTE - Foz do Iguaçu, Especialista em Gestão Ambiental pela PUC - Toledo, Sócia-Gerente da Empresa de Educação Ambiental Eduvivência. E-mail: cheila_noe@yahoo.com.br

2 Biólogo, Dr. Professor da Pontifícia Universidade Católica do Paraná. Professor do Programa de Pós-Graduação em Engenharia de Recursos Hídricos em Ambiental da Universidade Federal do Paraná. E-mail: mnolasc@terra.com.br. 


\section{Introdução}

Há algumas décadas as organizações preocupavam-se exclusivamente com a eficiência dos sistemas de produção, porém ao longo dos anos essa visão limitada do processo cedeu lugar a uma percepção mais abrangente do sistema, uma vez que o contexto de atuação das empresas tornavase mais complexo.

A preocupação ecológica passou então a afetar diretamente o ambiente dos negócios, em função da sua relevância para a qualidade de vida da sociedade e dos benefícios ambientais proporcionados. De forma geral, houve um entendimento que as medidas de proteção ambiental não têm o objetivo de impedir o desenvolvimento econômico, mas sim aliá-las às práticas de preservação e conservação dos recursos naturais e da eqüidade social. O termo desenvolvimento sustentável reflete exatamente esse sentido, uma vez que se conceitua como o desenvolvimento que satisfaz às necessidades das gerações atuais sem comprometer a capacidade das gerações futuras de satisfazer suas próprias necessidades.

Tradicionalmente as cobranças referentes à proteção ambiental eram consideradas um obstáculo ao crescimento da produção, demandando grandes investimentos de difícil recuperação. Donaire (1999) aponta que algumas empresas têm demonstrado a viabilidade de ganhos financeiros e proteção ao meio ambiente, sendo necessário possuir certa dose de criatividade e condições internas que possibilitem transformar as restrições e ameaças ambientais em oportunidades de negócio, por meio, por exemplo, do reaproveitamento de resíduos internamente, do desenvolvimento de novos processos produtivos com a utilização de tecnologias mais limpas, do desenvolvimento de produtos para um mercado cada vez maior de consumidores conscientizados com relação às questões ecológicas, entre outros.

Dessa forma, as empresas têm buscado a adoção de práticas ambientais compatíveis com o respeito às necessidades das futuras gerações. Assim, a hidrelétrica de Itaipu criou o Programa de Gerenciamento de Resíduos Sólidos (PGRS) da Itaipu Binacional, visando minimizar os impactos causados tanto pelos resíduos provenientes do processo de geração de energia da área industrial, quanto pelos resíduos oriundos das atividades realizadas nos escritórios da empresa.
O Programa Vai e Vem é uma das linhas de ação do Programa de Gerenciamento de Resíduos Sólidos da Itaipu e atua especificamente na gestão dos resíduos recicláveis gerados nas áreas da usina. Este trabalho teve, portanto, como objetivo principal, fazer uma análise deste programa, identificando os principais aspectos do ponto de vista ambiental, social, econômico e institucional, qual a percepção dos funcionários da Itaipu, estagiários, participantes do Programa de Iniciação e Incentivo ao Trabalho (PIIT) e terceirizados sobre o Programa Vai e Vem e quais adaptações seriam necessárias para o seu melhor aproveitamento.

\section{Materiais e métodos}

O estudo sobre o gerenciamento de resíduos sólidos da Itaipu Binacional foi realizado em diversos setores da empresa, onde foram coletados dados sobre a geração, separação e disposição final dos resíduos recicláveis produzidos nas áreas da usina.

Para obter maiores informações sobre o nível de conhecimento do público interno da Itaipu em relação ao PGRS, durante o mês de abril de 2006, foram aplicados questionários a 67 colaboradores da empresa, entre funcionários e estagiários da Itaipu, participantes do PIIT e funcionários terceirizados. Os questionários foram aplicados em sete diferentes áreas da organização, com o objetivo de obter um universo mais abrangente, possibilitando um melhor e mais confiável embasamento para o estudo.

O questionário abordava questões referentes à classificação dos resíduos gerados no ambiente de trabalho, o conhecimento sobre a destinação desses materiais, a opinião sobre a eficiência do trabalho de educação ambiental, a predisposição em colaborar com as propostas da equipe de educação ambiental corporativa e quais ações deveriam ser adotadas para um melhor funcionamento do programa.

\section{Resultados}

O Programa Vai e Vem tem como objetivo destinar à reciclagem os materiais recicláveis gerados em função das atividades da usina e, para viabilizar essa separação, conta com uma infra-es- 
trutura de lixeiras e contêineres identificados em todas as áreas da empresa, ficando sob responsabilidade do público interno descartar os resíduos na lixeira adequada. Diariamente o material é recolhido por empresas terceirizadas por meio de suas equipes de limpeza e os resíduos de papel, plástico e metal são encaminhados à Central de Triagem, que organiza esse material em fardos para posterior destinação.

Em 2003 a Itaipu firmou uma parceria com a Associação de Recicladores Ambientais de Foz do Iguaçu (ARAFOZ) passando a doar seus materiais recicláveis que são considerados de boa qualidade e já chegam enfardados à associação com o objetivo de fortalecê-la. A Itaipu opera ainda com outras duas formas de atuação no que tange aos resíduos recicláveis: favorecendo instituições assistenciais, pelo repasse dos materiais recicláveis de interesse financeiro às instituições que podem comercializá-los e gerar renda com o negócio; e a manutenção do fundo social criado pela empresa, que recebe a receita não operacional gerada pela venda dos materiais recicláveis e que a aplica em projetos sociais desenvolvidos pelo setor de responsabilidade social da empresa.

Analisando a diversidade de resíduos gerados pelo público interno da usina em seus respectivos locais de trabalho, pode-se constatar pelo questionário aplicado que o maior volume é de resíduos de papel, sendo que $88 \%$ dos entrevistados afirmaram produzir esse tipo de resíduo, e 84\% disseram gerar resíduos de plástico. Os resíduos orgânicos foram apontados por 37\% dos entrevistados, seguidos dos metais com 30\%, pilhas e baterias com $22 \%$ e vidros e óleos e/ou graxas com $10 \%$ cada.

Percebe-se que a maior parte dos resíduos produzidos na empresa é reciclável e já possuem destinação adequada, como os papéis, que em sua maioria são papéis brancos e considerados de boa qualidade para a reciclagem, os plásticos, principalmente copos descartáveis, e também os metais. Entretanto, cabe ressaltar os resíduos orgânicos, pois $37 \%$ dos entrevistados afirmaram gerálos na empresa, o que justificaria um estudo efetivo de viabilidade para a compostagem desse material, mesmo que em pequenas composteiras.

Com relação às pilhas e baterias utilizadas em veículos automotores, em rádios de comunicação, em celulares e em bancos de baterias para fornecimento de energia de emergência, há duas destinações diferentes, variando conforme característica do material: a venda do material para reciclagem ou a devolução aos respectivos fabricantes, para que estes adotem diretamente ou por meio de terceiros os procedimentos apropriados para reutilização, reciclagem, descontaminação ou disposição final ambientalmente adequada, conforme resolução No 257/99 do Conselho Nacional do Meio Ambiente (CONAMA). Este tipo de resíduo permanece adequadamente armazenado no Almoxarifado Central da Itaipu, obedecendo às normas ambientais até que seja feito o repasse aos fabricantes ou à recicladora. Já as pilhas e baterias portáteis aguardam definição para correta destinação, pois essas são adquiridas de diversos fabricantes e são inclusive importadas principalmente da China e, por esse motivo, permanecem armazenadas até que se defina a melhor destinação.

Os resíduos de vidro, apontados por 10\% dos entrevistados, ainda não são encaminhados à reciclagem por serem considerados um volume muito pequeno, porém poderia ser avaliada a possibilidade de disponibilizar uma área para a armazenagem desse material até que atingisse um volume interessante para o encaminhamento à reciclagem.

Os pneus utilizados nos veículos da usina, as sucatas metálicas, os cabos elétricos e os cartuchos de impressora (não passíveis de recarga) são armazenados e posteriormente os lotes dos materiais são doados às instituições assistenciais ou são vendidos para reciclagem. Com os cartuchos de impressora é adotado um sistema de troca mútua, onde o funcionário só recebe o cartucho carregado se devolver o cartucho vazio, evitando assim o descarte de cartuchos ainda funcionais. Já as lâmpadas fluorescentes comuns e compactas utilizadas nas áreas da usina são enviadas desde 1998 para descontaminação e reciclagem em empresas devidamente licenciadas e certificadas a um custo médio de $\mathrm{R} \$ 0,50$ por unidade, sendo que somente em 2005 a Itaipu encaminhou 26.855 lâmpadas para essas empresas.

Os entrevistados foram questionados sobre o conhecimento da destinação dos resíduos por eles produzidos na usina, onde $72 \%$ afirmaram saber qual é esse destino e $27 \%$ disseram não ter esse conhecimento. Analisando as respostas dos entrevistados que afirmaram conhecer a destinação, 14\% não souberam descrever qual seria esse destino ou deram respostas incoerentes e, dessa 
forma, verifica-se que o índice de pessoas que não possuem conhecimento sobre a destinação do material eleva-se para 39\%. Pode-se identificar que a maior parte dessas pessoas são funcionários de empresas terceirizadas e estagiários da Itaipu e que atuam na empresa entre 1 a 5 anos. Essa constatação afirma a necessidade de um trabalho educativo direcionado a esse público, pois são grupos onde ocorre uma rotatividade considerável de pessoas e por esse motivo orientações e cursos de capacitação devem ser realizados periodicamente e em todas as áreas da empresa, pois todos os setores da Itaipu apresentaram referências similares de desconhecimento do programa Vai e Vem.

A Itaipu atua com um trabalho de educação ambiental corporativa, visando internalizar na cultura de seu público corporativo e nos costumes da organização o espírito de responsabilidade socioambiental, fundamentado nos princípios e valores globais, ligado à ética do cuidado e baseado em três vertentes: água, energia e resíduos. Com relação aos resíduos, busca-se uma reeducação do público interno, não enfocando o equacionamento da problemática dos resíduos apenas na reciclagem, mas na acentuada descartabilidade que se impôs pela cultura consumista que se estabeleceu na nossa sociedade. Para agilizar e articular informações e responsabilidades foi formada uma rede interna de educadores ambientais, tendo um representante em cada área da usina. Analisando a importância do trabalho desenvolvido pela equipe de educação ambiental corporativa, 98\% dos entrevistados consideraram este trabalho importante e apontaram as dicas para redução, reaproveitamento e reciclagem e as informações sobre os problemas ambientais causados pelas ações como as principais contribuições dos trabalhos educativos que são realizados. Essa avaliação reafirma a necessidade dessas ações de educação ambiental na empresa, pois, segundo Castro e Canhedo (2005), a participação do homem como sujeito na sociedade, na cultura e na história se faz à medida que é educado para conscientizar-se e assumir suas responsabilidades de ser humano.

Dentre as ações realizadas pela equipe de educação ambiental corporativa, pode-se destacar a proposta de substituição do uso dos copos plásticos descartáveis por canecas ou copos de vidro ou qualquer outro material não descartável, pois na Itaipu o consumo médio de copos descartáveis chega a 342.000 unidades por mês, totali- zando mais de 4 milhões de unidades por ano. Neste estudo verificou-se que $63 \%$ do público interno da usina ainda utilizam esse material para consumo de bebidas, porém, desse total, $76 \%$ está disposto a colaborar com a proposta, substituindo seus copos. Já as pessoas que são contrárias à idéia da troca apontaram argumentos como a falta de locais para lavar os copos, impossibilidade de substituição, pois trabalha no campo, falta de higiene e comodismo. Os entrevistados apontaram as ações necessárias para um melhor funcionamento do programa, como a realização mais freqüente de diálogos interativos realizados pela equipe de educação ambiental, com 81\%, e capacitação das equipes de copa e limpeza, com 64\%. As equipes de copa são responsáveis pela disposição de resíduos diários como pó de café e chá que, quando misturados com resíduos recicláveis como o papel, podem inviabilizar a reciclagem, e as equipes de limpeza têm a função de coletar separadamente os materiais recicláveis dos não recicláveis, sendo essencial a colaboração dessas equipes para o bom andamento do programa. Outros itens apontados pelos entrevistados foram a realização de cursos para funcionários terceirizados e a criação de normas claras para serem cumpridas pelos empregados, com 48\% cada um; a realização de cursos para os estagiários e PIITs no início do estágio na empresa, com 39\%; e melhorias na infraestrutura das áreas, como o acesso às pias para viabilizar a lavagem dos copos de vidro ou o fornecimento de lixeiras para algum setor onde haja carência, com 22\%.

Com base no levantamento de dados realizado e nos questionários aplicados, pode-se perceber que o PGRS - Vai e Vem da Itaipu atua na busca de procedimentos, mecanismos e padrões de consumo que atendam a um posicionamento responsável no que envolve a gestão dos resíduos sólidos.

Uma empresa como a Itaipu Binacional, que no início foi considerada causadora, pela própria atividade em si, de impactos ambientais e sociais negativos para a região, deve adotar medidas compensatórias e, nesse sentido, o PGRS - Vai e Vem contempla uma série de benefícios ambientais, sociais, econômicos e institucionais.

Do ponto de vista ambiental, salienta-se a eliminação dos lixões da empresa onde antigamente eram depositados todos os resíduos gerados na usina sem nenhum critério sanitário de pro- 
teção ambiental ou social. Uma nova vala para o depósito dos resíduos era aberta a cada seis meses aproximadamente, ocasionando a poluição do solo, ar e água e colocando em risco a saúde de pessoas que invadiam a área para a coleta de materiais. Com o início do programa, os resíduos não recicláveis passaram a ser encaminhados ao aterro sanitário municipal e os demais para reciclagem, evitando a disposição de um volume imenso de materiais na natureza. Outro benefício ambiental refere-se à minimização da produção de resíduos, uma vez que há um trabalho de educação ambiental voltado à redução do consumo de materiais.

Com relação à questão social do programa, verifica-se uma preocupação para que a sociedade seja beneficiária dos recursos gerados em função do programa. Assim, a Itaipu repassa às entidades assistenciais do município os resíduos recicláveis produzidos na empresa para que essas possam obter renda com a sua comercialização. Além disso, há o fundo social que foi criado pela empresa. Esse fundo recebe a receita não operacional gerada pela venda dos materiais recicláveis (os que não são doados às entidades), e a aplica em projetos sociais desenvolvidos pelo setor de responsabilidade social da empresa, estabelecendo assim uma relação de atenção e cuidado com a comunidade.

$\mathrm{Na}$ questão econômica, pode-se identificar a busca pelo aumento da eficiência no uso de matérias-primas e insumos básicos, mediante a redução dos desperdícios, como é o caso da proposta para a substituição dos copos descartáveis; do reaproveitamento de materiais, com o uso de ambos os lados das folhas de papel mediante a confecção de blocos de rascunhos; e da reciclagem propriamente dita, com a coleta seletiva dos materiais, possibilitando, assim, uma contenção dos recursos financeiros aplicados na compra de insumos.

E por outro lado a Itaipu Binacional fortalece sua imagem institucional, por meio da caracterização de uma entidade comprometida e responsável com os recursos naturais e com a sociedade, o que pode se traduzir em funcionários mais motivados e até melhores fornecedores. O Programa Vai e Vem também trabalha com a cultura e os costumes da organização, visando a adoção do espírito de responsabilidade por meio da participação de todos os seus colaboradores, o que a valoriza ainda mais enquanto empresa.

\section{Conclusões}

O presente estudo permitiu documentar o processo adotado pela Itaipu Binacional com os resíduos recicláveis no Programa Vai e Vem, como uma das linhas de ação de seu programa de gerenciamento de resíduos sólidos;

O Vai e Vem pode ser considerado um programa abrangente, pois não visa apenas a coleta seletiva dos resíduos, mas incentiva seus colaboradores a uma reflexão crítica e ampla sobre os valores da nossa sociedade de consumo, do modo de produção capitalista, do ciclo de vida dos produtos, e da responsabilidade de cada um enquanto indivíduo ativo da comunidade e, dessa forma, pode servir de modelo para outras empresas, tanto públicas quanto privadas, na elaboração e desenvolvimento de seus programas de gerenciamento de resíduos sólidos.

\section{Agradecimentos}

A autora agradece ao professor Marcelo Antunes Nolasco pela Orientação da Monografia de Conclusão do Curso de Especialização e incentivo e ao colega Irineu Braz Torrezan pelo auxílio incondicional na elaboração deste trabalho.

\section{Referências}

BRASIL. Conselho Nacional de Meio Ambiente. Resolução N. ${ }^{\circ}$ 257/1999. Disponível em: <http:// www.mma.gov.br//port/conama/res/res99/ res25799.html>. Acesso em: 18 mar. 2006.

CASTRO, M.; CANHEDO, S. Educação ambiental como instrumento de participação. In: PHILIPPI, A.; PELICIONI, M. Educação ambiental e sustentabilidade. Barueri: Manole, 2005. p. 59-83.

DONAIRE, D. Gestão ambiental na empresa. 2. ed. São Paulo, SP: Atlas, 1999.
Recebido: 13/04/2005 Aprovado: 30/09/2005 